Check for updates

Cite this: New J. Chem., 2021, 45, 17951

Received 24th June 2021

Accepted 23rd August 2021

DOI: 10.1039/d1nj03098a

rsc.li/njc

\section{Sequestration of tetravalent neptunium from acidic feeds using diglycolamide-functionalized dendrimers in a room temperature ionic liquid: extraction, spectroscopic and electrochemical studies $\uparrow$}

\author{
Parveen K. Verma, (D) ${ }^{a}$ Rajesh B. Gujar, ${ }^{a}$ Bholanath Mahanty, ${ }^{a}$ Andrea Leoncini, ${ }^{b}$ \\ Jurriaan Huskens, (D ${ }^{\mathrm{b}}$ Willem Verboom (D) ${ }^{\mathrm{b}}$ and Prasanta K. Mohapatra (D) *a
}

\begin{abstract}
Quantitative extraction of $\mathrm{Np}(\mathrm{IV})$ was achieved using a room temperature ionic liquid containing submillimolar concentrations of two poly(propyleneimine) based dendrimer ligands with four $\left(\mathbf{L}_{\mathbf{l}}\right)$ and eight $\left(\mathbf{L}_{\text {III }}\right)$ diglycolamide (DGA) moieties from nitric acid solutions. The extraction of the metal ion followed a cation exchange mechanism with decreasing extraction with increasing $\mathrm{HNO}_{3}$ concentration up to $4 \mathrm{M}$, the major exchanging species being $\mathrm{Np}\left(\mathrm{NO}_{3}\right)_{3} \mathrm{~L}^{+}$. Beyond this acidity an increased metal ion extraction was seen, which was attributed to an anion exchange mechanism. UV-visible spectrophotometric studies showed a different nature of the extracted $\mathrm{Np}-\mathbf{L}\left(\mathbf{L}_{\mathbf{l}}\right.$ or $\left.\mathbf{L}_{\| 1}\right)$ complexes in the ionic liquid and molecular diluent. Quantitative back extraction of $\mathrm{Np}(\mathrm{IV})$ was achieved by using aqueous complexing agents. Cyclic voltametric studies of the extracted complexes exhibited differences in the electrondonating ability of the two ligands towards $\mathrm{Np}$ (IV). Both ligands showed a non-reversibility or a quasireversible nature of the $\mathrm{Np}$ reduction couple. The radiation stability of the present extraction system was not so high.
\end{abstract}

\section{Introduction}

Nuclear power production involves the controlled fission of a fissile nuclide such as ${ }^{235} \mathrm{U}$ in a nuclear reactor. It results in the formation of a myriad fission products, while trans-uranium elements such as neptunium, plutonium, americium, etc. are formed as byproducts. For sustainable production of nuclear power, an effective way to manage the nuclides with very high radiotoxicities is required so as to minimize and mitigate their hazardous effects on the general population. ${ }^{1}$ This is being achieved to a large extent using a 'closed' fuel cycle strategy wherein the fissile materials ( $\mathrm{U}$ and Pu containing the unused ${ }^{235} \mathrm{U}$ in the case of the former and the generated ${ }^{239} \mathrm{Pu}$ in the case of the latter) are separated from the fission products such as rare earth ions, platinum group metals, and alkali and alkaline earth metals such as $\mathrm{Cs}$, Sr, and Ba, and activation

\footnotetext{
${ }^{a}$ Radiochemistry Division, Bhabha Atomic Research Centre, Mumbai - 400085 , India. E-mail: mpatra@barc.gov.in

${ }^{b}$ Laboratory of Molecular Nanofabrication, MESA + Institute for Nanotechnology, University of Twente, P. O. Box 217, 7500 AE Enschede, The Netherlands. E-mail:w.verboom@utwente.nl

$\dagger$ Electronic supplementary information (ESI) available: Equilibration time, diffusion constant calculation, and oxidation state ${ }^{239} \mathrm{~Np}$. See DOI: 10.1039/d1nj03098a
}

products such as $\mathrm{Np}$ and Am (termed as the minor actinides) by the well known PUREX (Plutonium Uranium Redox EXtraction) process using $30 \%$ TBP (tri- $n$-butyl phosphate) in a paraffinic hydrocarbon diluent. ${ }^{2}$ The raffinate stream from the PUREX process contains highly hazardous fission products and minor actinides which are proposed to be vitrified in a glass matrix and buried underground in deep geological repositories. ${ }^{3,4}$ This, however, requires long surveillance of the vitrified blocks to monitor their integrity under natural calamity conditions such as earthquakes and volcanic eruptions causing a huge economic burden. However, a recent strategy, termed as 'actinide partitioning ${ }^{4-6}$ proposes to separate the minor actinides, with their half-lives ranging from thousands of years to several millions of years, and subsequently transmute the long-lived radionuclides to short-lived products thereby reducing the surveillance period drastically.

${ }^{237} \mathrm{~Np}$, with a half-life of $2.14 \times 10^{6}$ years, is considered one of the most long-lived radionuclides in high level liquid waste (HLLW) and there have been several attempts to separate Np from acidic feeds akin to HLLW. ${ }^{7}$ Diglycolamide (DGA) ligands have been employed for the separation of $\mathrm{Np}$ from acidic feeds and appeared to be quite effective for this purpose. ${ }^{8-10}$ DGAbased ligands such as TODGA ( $\left(N, N, N^{\prime}, N^{\prime}\right.$-tetra- $n$-octyl diglycolamide) 

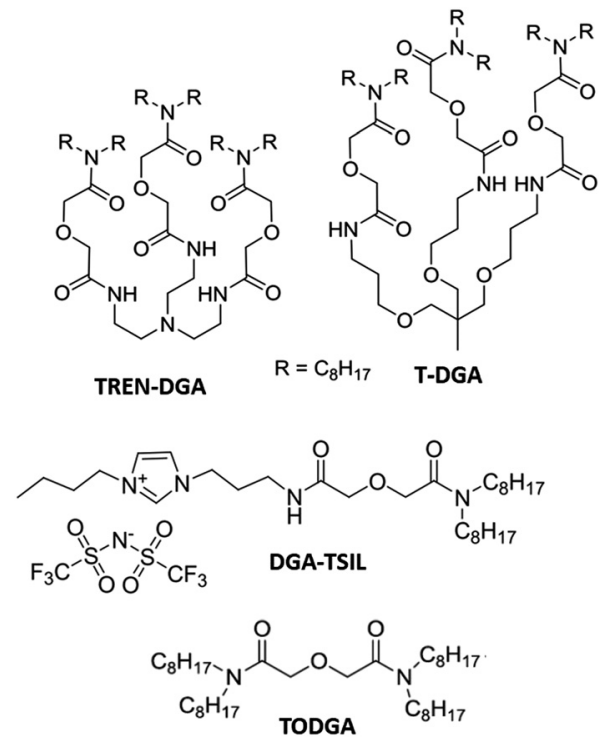

Fig. 1 Structure of TODGA and some other multiple DGAs.

(Fig. 1) have been found to be quite promising for minor actinide partitioning. ${ }^{11-13}$ Their extraction mechanism is based on a reverse micellar aggregation of 3-4 TODGA molecules in a nonpolar diluent such as $n$-dodecane. ${ }^{14,15}$ Subsequent attempts to synthesize several multiple DGA-containing ligands such as calix[4]arenes, ${ }^{16}$ tripodals, $^{17}$ pillar[5] arenes $^{18}$ and DGA-based dendrimer $^{19}$ ligands have shown extremely promising results for the extraction of trivalent f-cations. However, these ligands have not been evaluated for the separation of $\mathrm{Np}$ from acidic feeds as encountered in the HLLW. Our recent study to separate $\mathrm{Np}$ (IV) from acidic feeds using two DGA-based PPI (polypropylene imine) dendrimers, a Gen 1 dendrimer with four DGA moieties $\left(\mathbf{L}_{\mathbf{I}}\right)$ and a Gen 2 dendrimer with eight DGA moieties ( $\left.\mathbf{L}_{\mathbf{I I}}\right)$ was highly promising (Fig. 2). ${ }^{20}$

All these above studies used molecular diluents such as $n$-dodecane and its mixtures, which are considered hazardous due to their VOC contents. Room temperature ionic liquids (RTIL) are neoteric diluents extensively studied for metal ion extraction in view of their low volatility and nonflammability. ${ }^{21-26}$ Also, wide electrochemical windows are encountered in the case of RTIL-based solvents making them promising for direct electrowinning of the extracted metal ions. ${ }^{27}$ In view of the promising results reported with the DGAbased dendrimer ligands in molecular diluents, it was of great relevance to evaluate these ligands in the $\mathrm{RTIL}, \mathrm{C}_{4} \mathrm{mim} \cdot \mathrm{NTf}_{2}$ (1-butyl-3-methylimidazolium bis(trifluoromethane)sulfonimide). In this solvent, a better extraction efficiency is expected in view of the prevailing cation exchange mechanism. ${ }^{21,24,26}$

The present work involves the extraction of $\mathrm{Np}$ (Iv) from nitric acid feeds using $\mathbf{L}_{\mathbf{I}}$ and $\mathbf{L}_{\mathbf{I I}}$ in $\mathrm{C}_{4} \mathrm{mim} \cdot \mathrm{NTf}_{2}$. Solvent extraction studies were carried out to get an idea about the nature of the extracted species. UV-visible spectrophotometric studies were carried out to understand the redox speciation of $\mathrm{Np}$ based on the absorbance of various species. Finally, cyclic voltammetric
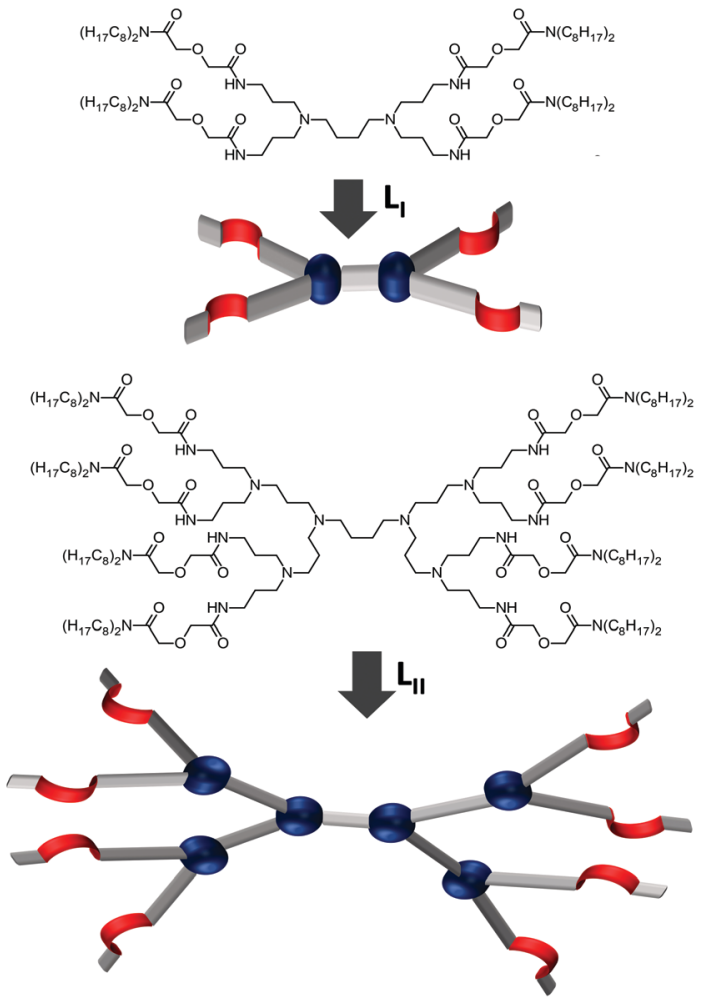

Fig. 2 Structure of poly(propylene imine) diaminobutane dendrimers $\left(\mathbf{L}_{1}\right.$ and $\left.\mathbf{L}_{11}\right)$ and its cartoon representation.

studies were performed. To our knowledge, this is the first report on the extraction of $\mathrm{Np}$ (Iv) using DGA-based dendrimers in a RTIL, which may find application in radioactive waste management, based on the promising results.

\section{Results and discussion}

\section{Solvent extraction studies}

The DGA-functionalized poly(propylene imine) diaminobutane dendrimers $\mathbf{L}_{\mathbf{I}}$ (Gen I) and $\mathbf{L}_{\mathbf{I I}}$ (Gen II) (Fig. 2) dissolved in $\mathrm{C}_{4} \mathrm{mim} \cdot \mathrm{NTf}_{2}$ were evaluated for the extraction of $\mathrm{Np}(\mathrm{Iv})$ from nitric acid solutions. The uptake of water and nitric acid was also studied in the absence as well as in the presence of the ligands. The acid and water uptake were found to be in the similar (within error limits) range due to the very small concentration of ligands $\left(\left[\mathbf{L}_{\mathbf{I}}: 1 \times 10^{-4} \mathbf{M}\right.\right.$ and $\left.\mathbf{L}_{\mathbf{I I}}: 1 \times 10^{-5} \mathrm{M}\right)$ used in the present studies. Most of the acid or water uptake is decided by the $\mathrm{C}_{4} \mathrm{mim} \cdot \mathrm{NTf}_{2}$ medium (Table 1 ). The extraction kinetics of $\mathrm{Np}$ (Iv) for $\mathbf{L}_{\mathbf{I}}$ and $\mathbf{L}_{\mathbf{I I}}$ dissolved in $\mathrm{C}_{4} \mathrm{mim} \cdot \mathrm{NTf}_{2}$ was found to be relatively slow as compared to the molecular diluent ${ }^{20}$ and equilibrium was achieved in 30-40 minutes of equilibration (ESI). The preliminary studies showed a high $D_{\mathrm{Np}}$ for $\mathbf{L}_{\mathbf{I I}}$ compared to $\mathbf{L}_{\mathbf{I}}$ even at $1 \times 10^{-4} \mathrm{M}$ ligand concentration. The high $D$ value has the intrinsic problem of lower ${ }^{239} \mathrm{~Np}$ counts in the aqueous phase resulting in poor reproducibility of the data obtained in triplicate. Therefore, the concentration of $\mathbf{L}_{\text {II }}$ was 
Table 1 Water, acid and distribution ratios of $\mathrm{Np}(\mathrm{IV})\left(D_{\mathrm{Np}}\right)$ by neat $\mathrm{C}_{4} \mathrm{mim}$. $\mathrm{NTf}_{2}$ at different acidities at $298 \mathrm{~K}$

\begin{tabular}{llll}
\hline$\left[\mathrm{HNO}_{3}\right], \mathrm{M}$ & Water uptake (\%) & Acid uptake (\%) & $D_{\mathrm{Np}}$ \\
\hline 0.5 & - & - & $<0.01$ \\
1 & 1.57 & 3.4 & $<0.01$ \\
2 & 1.88 & 4.5 & 0.03 \\
3 & 2.30 & 5.7 & 0.12 \\
6 & 3.58 & 12.5 & 0.27 \\
\hline
\end{tabular}

lowered by 10 times $\left(1 \times 10^{-5} \mathrm{M}\right)$, while that of $\mathbf{L}_{\mathbf{I}}$ was kept at $1 \times 10^{-4} \mathrm{M}$ in the subsequent studies.

Since these concentrations of the ligands are in the submillimolar region, it is important to determine the uptake of $\mathrm{Np}$ (Iv) by the blank (without any ligand) $\mathrm{C}_{4} \mathrm{mim} \cdot \mathrm{NTf}_{2}$ in the studied acidity range (Table 1 ). The extraction of $\mathrm{Np}$ (Iv) was found to increase with the feed acidity in $\mathrm{C}_{4} \mathrm{mim} \cdot \mathrm{NTf}_{2}$ due to anion exchange of the anionic Np-nitrate complex (specifically at high acidity) ${ }^{28}$ with the $\mathrm{NTf}_{2}{ }^{-}$of $\mathrm{C}_{4} \mathrm{mim} \cdot \mathrm{NTf}_{2}$ according to

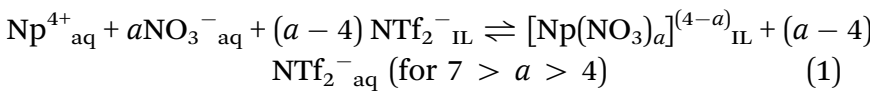

where the subscripts 'IL' and 'aq' denote species present in the ionic liquid and aqueous phase, respectively. In the extraction studies with $\mathbf{L}_{\mathbf{I}}$ and $\mathbf{L}_{\mathbf{I I}}$ blank corrections for $D_{\mathrm{Np}}$ were made at the higher acidities.

A regular decrease in the $D_{\mathrm{Np}}$ was observed for both ligands with increasing $\mathrm{HNO}_{3}$ concentration till $4 \mathrm{M} \mathrm{HNO}_{3}$, whereupon the $\mathrm{Np}$ (Iv) extraction increased. Rout et al. observed a similar extraction profile for $\mathrm{Pu}(\mathrm{Iv})$ using $N, N$-dioctyl-2-(3-methylimidazolium)acetamide bis(trifluoromethane sulfonyl) imide (DOAIm $\cdot \mathrm{NTf}_{2}$ ) from $\mathrm{C}_{4} \mathrm{mim} \cdot \mathrm{NTf}_{2}$ medium. The enhanced extraction of $\mathrm{Pu}(\mathrm{Iv})$ at higher acidity is mainly governed by anion exchange of $\left[\mathrm{Pu}\left(\mathrm{NO}_{3}\right)_{5}\left(\mathrm{H}_{2} \mathrm{O}\right)\right]^{-}$or $\left[\mathrm{Pu}\left(\mathrm{NO}_{3}\right)_{6}\right]^{2-}$ species with the $\mathrm{NTf}_{2}{ }^{-}$of the $\mathrm{C}_{4} \mathrm{mim} \cdot \mathrm{NTf}_{2}$ phase. ${ }^{29}$ A similar anion exchange reaction is also possible for the present study on $\mathrm{Np}$ (Iv) extraction at $>4 \mathrm{MHNO}_{3}$. An anion exchange mechanism for the extraction of tetravalent actinides with amines dissolved in ionic liquids was also observed by Ansari et al. ${ }^{30}$ This Np(Iv) extraction behaviour up to $4 \mathrm{M} \mathrm{HNO}_{3}$, is commonly observed for a cation exchange mechanism of metal ion uptake from RTIL media. ${ }^{21,24}$ A cation exchange mechanism for the extraction of $\mathrm{Np}$ (Iv) was also observed by others using different neutral extractants dissolved in an ionic liquid. ${ }^{31-33}$ Although the acid variation studies suggested a cation exchange mechanism of the metal ion extraction (Fig. 3), ligand, nitrate and $\mathrm{C}_{4} \mathrm{mim}^{+}$variation studies were carried out to obtain information about the stoichiometry of the extracted species into the $\mathrm{C}_{4} \mathrm{mim} \cdot \mathrm{NTf}_{2}$ medium by the two ligands. The nitrate ion
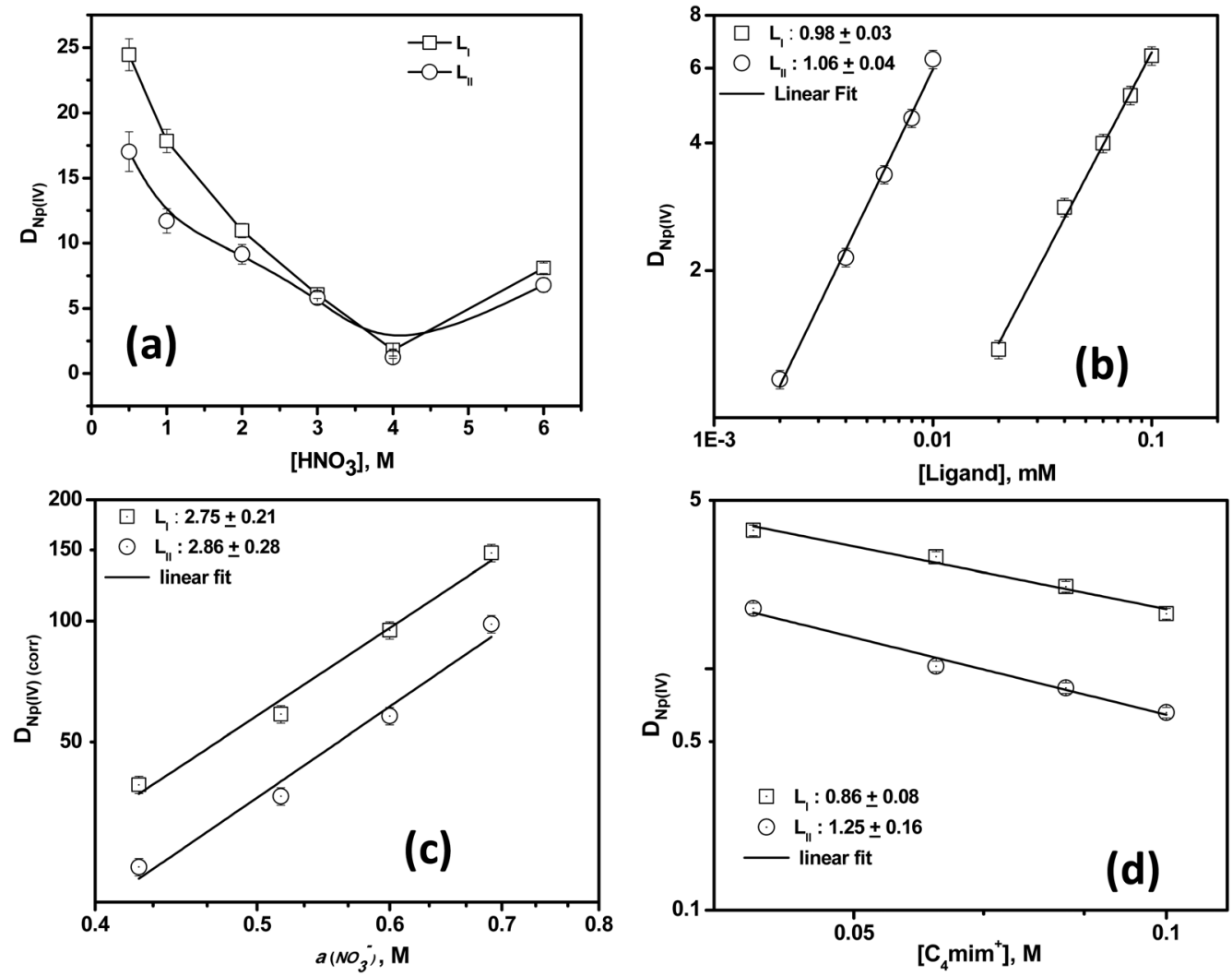

Fig. 3 Extraction of $\mathrm{Np}(\mathrm{IV})$ as a function of varying (a) acidity using $\left[\mathrm{L}_{1}\right]: 1 \times 10^{-4} \mathrm{M}$ and $\left[\mathrm{L}_{11}\right]: 1 \times 10^{-5} \mathrm{M}$ ligand solutions; (b) ligand concentration at $3 \mathrm{M}$ $\mathrm{HNO}_{3}$ and (c) nitrate ion concentration and (d) $\mathrm{C}_{4} \mathrm{mim}^{+}$concentration using $\left[L_{1}\right]: 1 \times 10^{-4} \mathrm{M}$ and $\left[L_{11}\right]: 1 \times 10^{-5} \mathrm{M}$ ligand solutions, dissolved in $\mathrm{C}_{4}$ mim. $\mathrm{NTf}_{2} ; \mathrm{T}: 298 \mathrm{~K}$. 
Table 2 Comparison of slope analysis results of the log-log plot of nitrate and ligand variation for $\mathrm{Np}$ extraction by $\mathrm{L}_{1}$ and $\mathrm{L}_{\| 1}$ in $\mathrm{C}_{4} \mathrm{mim} \cdot \mathrm{NTf}_{2}$ and $5 \%$ isodecanol $+95 \% n$-dodecane $e^{20}$

\begin{tabular}{llllll}
\hline & \multicolumn{2}{l}{ Nitrate variation ${ }^{a}$} & & \multicolumn{2}{c}{ Ligand variation $^{b}$} \\
\cline { 2 - 3 } \cline { 5 - 6 } Ligand & Mol. dil. & RTIL & & Mol. dil. & \multicolumn{2}{l}{ RTIL } \\
\hline $\mathbf{L}_{\mathbf{I}}$ & $3.77 \pm 0.47$ & $2.75 \pm 0.21$ & & $1.19 \pm 0.01$ & $1.06 \pm 0.04$ \\
$\mathbf{L}_{\text {II }}$ & $3.74 \pm 0.36$ & $2.86 \pm 0.28$ & & $0.98 \pm 0.02$ & $0.98 \pm 0.03$ \\
\multicolumn{2}{l}{${ }^{a}$ At $0.5 \mathrm{M} \mathrm{HNO}_{3} \cdot{ }^{b}$ At $3 \mathrm{M} \mathrm{HNO}_{3}}$. & & \\
\hline
\end{tabular}

complexation corrected distribution ratio of $\mathrm{Np}^{4+}, D_{\mathrm{Np}(\mathrm{corr})}$, (for derivation and other details see the ESI $\dagger$ ) with the activity of nitrate ions in the aqueous phase were used for the slope analysis in nitrate variation experiments. ${ }^{34,35}$ Slope analysis of the $\log D_{\mathrm{Np}}$ versus $\log \left[\mathrm{L}\left(\mathbf{L}_{\mathbf{I}} / \mathbf{L}_{\mathbf{I I}}\right)\right], \log D_{\mathrm{Np}(\operatorname{corr})} v s . \log a_{\left(\mathrm{NO}^{-}\right)}$and $\log D_{\mathrm{Np}}$ vs. $\log \left[\mathrm{C}_{4} \mathrm{mim}^{+}\right]$plots for ligand and nitrate and $\mathrm{C}_{4} \mathrm{mim}^{+}$variation (Table 2 and Fig. 3), respectively, indicated the extraction of $\mathrm{Np}\left(\mathrm{NO}_{3}\right)_{3} \mathrm{~L}^{+}$species (Fig. 4) with the equilibrium reaction as given by eqn (2):

$$
\begin{gathered}
\mathrm{Np}^{4+}{ }_{\text {aq }}+\mathrm{L}_{\mathrm{IL}}+3 \cdot \mathrm{NO}_{3}{ }^{-}{ }_{\text {aq }}+\mathrm{C}_{4} \operatorname{mim}_{\mathrm{IL}}{ }^{+} \rightarrow\left[\mathrm{Np}\left(\mathrm{NO}_{3}\right)_{3} \cdot \mathrm{L}\right]_{\mathrm{IL}}{ }^{+} \\
+\mathrm{C}_{4} \mathrm{mim}^{+}{ }_{\text {aq }}
\end{gathered}
$$

The decrease in the $D_{\mathrm{Np}}$ value with increasing $\mathrm{C}_{4} \mathrm{mim}^{+}$in the aqueous phase also supports the proposed cation-exchange mechanism of $\mathrm{Np}^{4+}$ extraction based on the acid variation studies.

The present system offers high $D_{\mathrm{Np}(\mathrm{IV})}$ values at $0.5 \mathrm{M} \mathrm{HNO}_{3}$ in $\mathrm{C}_{4} \mathrm{mim} \cdot \mathrm{NTf}_{2}$ even at sub-millimolar ligand concentrations. The $D_{\mathrm{Np}(\mathrm{IV})}$ values for different extraction systems are compared with those of the present system in Table 3 . Normalizing the $D_{\mathrm{Np}(\mathrm{IV})}$ values with respect to ligand concentration (assuming $1: 1 \mathrm{M}:$ L stoichiometry) shows high $D_{\mathrm{Np}(\mathrm{IV})}$ values compared to the other systems. Previous studies suggested a solvation

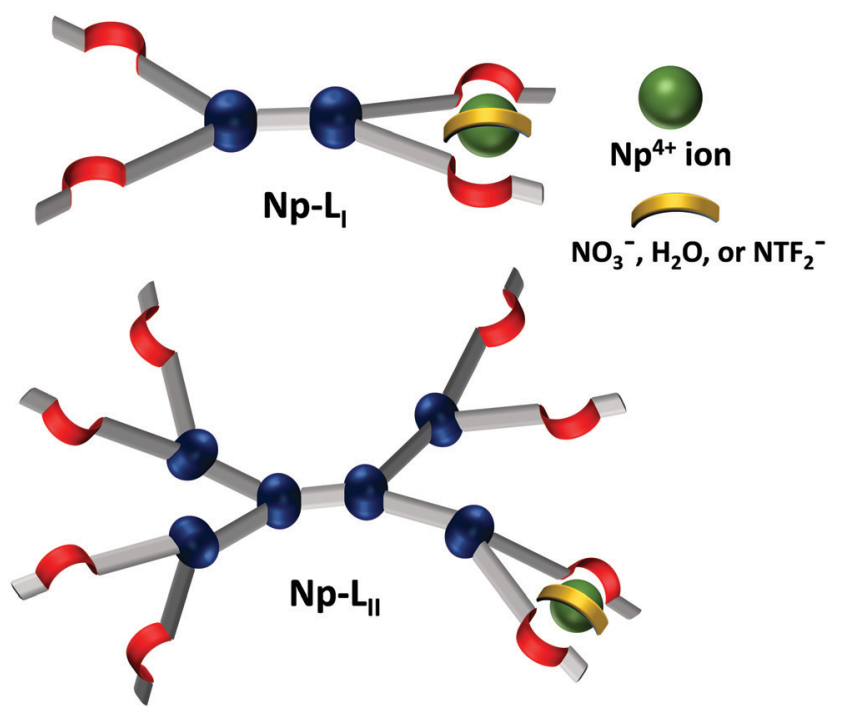

Fig. 4 Structure of the extracted $N p(I v)-L\left(L: L_{1}\right.$ or $L_{11}$ ) complex in $C_{4}$ mim. $\mathrm{NTf}_{2}$.
Table 3 Distribution coefficients of tetravlent actinides $\left(D_{M(I V)}\right)$ using different extractants (Fig. 1 and 2) dissolved in $\mathrm{C}_{4} \mathrm{mim} \cdot \mathrm{NTf}_{2} /$ molecular solvent ${ }^{a}$; from $\mathrm{HNO}_{3}$ media, $\mathrm{T}: 298 \mathrm{~K}$

\begin{tabular}{llll}
\hline Extractant & {$[$ Ligand], M } & $D_{\mathrm{M}(\mathrm{IV})}$ & Ref. \\
\hline TODGA $^{b}$ & $1 \times 10^{-2}$ & $<5\left(250 \pm 35^{c}\right)^{d}$ & 28 and 37 \\
DGA-TSIL $^{b}$ & $3.6 \times 10^{-2}$ & 7.6 & 33 \\
T-DGA $^{c}$ & $1 \times 10^{-3}$ & $3227 \pm 40(145 \pm 1)^{e}$ & 38 and 39 \\
TREN-DGA $^{c}$ & $1 \times 10^{-3}$ & $4.0 \pm 0.1\left(0.25 \pm 0.1^{c}\right)$ & 38 and 40 \\
$\mathbf{L}_{\mathbf{I}}{ }^{c}$ & $1 \times 10^{-4}$ & $17.4 \pm 0.87(70.26 \pm 4.27)$ & 20 and 41 \\
$\mathbf{L}_{\text {II }}{ }^{b}$ & $1 \times 10^{-4}$ & $97.2 \pm 3.71(77.48 \pm 3.87)$ & 20 and 41 \\
$\mathbf{L}_{\mathbf{I}}{ }^{b}$ & $1 \times 10^{-4}$ & $24.45 \pm 1.22(8.48 \pm 0.21)$ & p.w. $^{20}$ \\
$\mathbf{L}_{\text {II }}$ & $1 \times 10^{-5}$ & $17.05 \pm 0.1(21.31 \pm 0.64)^{f}$ & p.w.
\end{tabular}

${ }^{a}$ Values in parenthesis: $5 \%$ isodecanol $+95 \% n$-dodecane at $3 \mathrm{M} \mathrm{HNO}_{3}$. ${ }^{b} \mathrm{~Np}$ (Iv) at $0.5 \mathrm{M} \mathrm{HNO}_{3} \cdot{ }^{c} \mathrm{Pu}(\mathrm{Iv})$ at $3 \mathrm{M} \mathrm{HNO}_{3} .{ }^{d}$ [TODGA]: $0.05 \mathrm{M}$. ${ }^{e}\left[\right.$ T-DGA]: $2.9 \times 10^{-3}$ M. $^{f}\left[\mathbf{L}_{\mathbf{I I}}\right]: 1 \times 10^{-4} \mathrm{M}$; p.w.: present work.

mechanism for the extraction of $\mathrm{Np}$ (IV) by $\mathbf{L}_{\mathbf{I}}$ and $\mathbf{L}_{\mathbf{I I}}$ in a molecular diluent. ${ }^{20}$ For both ligands the formation of $1: 1$ species was observed both in ionic liquid and molecular diluents, though the nature of the species is distinctly different. It is worthy to compare the UV-Vis spectra of the $\mathrm{Np}$ (Iv)-L extracts from the two media to gain some more insight into the nature of the extracted species. Cocalia et al. ${ }^{36}$ suggested the formation of similar extracted species in the case of trivalent and hexavalent actinides, but not of tetravalent ions, from either a RTIL or a molecular diluent.

\section{Absorption studies}

The visible-near infrared (vis-NIR) spectra of the Np(Iv) extract with $\mathbf{L}_{\mathbf{I}} / \mathbf{L}_{\mathbf{I I}}$ dissolved in $\mathrm{C}_{4} \mathrm{mim} \cdot \mathrm{NTf}_{2}$ were recorded in the wavelength range of 600-1000 $\mathrm{nm}$ and compared with the $\mathrm{Np}-\mathbf{L}_{\mathbf{I}} / \mathbf{L}_{\mathbf{I I}}$ extract spectra in $5 \%$ isodecanol $+n$-dodecane. The vis-NIR spectrum of $\mathrm{Np}$ (Iv) aq shows several absorption lines due to the $\mathrm{f}-\mathrm{f}$ transitions at $0.5 \mathrm{M} \mathrm{HNO}_{3}{ }^{42}$ The $\mathrm{Np}$ (Iv) system is isoelectronic with that of $\mathrm{Nd}^{3+}$ with the $\mathrm{f}^{3}$ outer electronic configuration. ${ }^{43-46}$ The optical transitions for $\mathrm{Np}(\mathrm{Iv})$ ( $\mathrm{f}^{3}$ system) are mainly arising from the ${ }^{4} \mathrm{I}_{9 / 2}$ state to the higher ${ }^{4} \mathrm{I}_{11 / 2},{ }^{4} \mathrm{I}_{13 / 2}$, ${ }^{2} \mathrm{G}_{7 / 2},{ }^{2} \mathrm{H}_{9 / 2}$, etc., states. ${ }^{43,47-50}$

The vis-NIR spectra of the extracted Np- $\mathbf{L}_{\mathbf{I}}$ and Np- $\mathbf{L}_{\text {II }}$ complexes look similar in 5\% isodecanol $+95 \% n$-dodecane medium (Fig. 5(a) and (b)), suggesting a similar ligand environment around $\mathrm{Np}$ (Iv) in both species in line with the speciation studies performed previously. ${ }^{20}$ Although formation of $1: 1$ complexes was observed for $\mathrm{Np}$ (IV) extraction by $\mathbf{L}_{\mathbf{I}}$ and $\mathbf{L}_{\mathbf{I I}}$ into the RTIL, their vis-NIR spectra were very different (Fig. 5(c) and (d)).

The exact symmetry analysis of Np-L $\left(\mathbf{L}_{\mathbf{I}}\right.$ and $\left.\mathbf{L}_{\mathbf{I I}}\right)$ extracted complexes in $\mathrm{C}_{4} \mathrm{mim} \cdot \mathrm{NTf}_{2}$ is difficult from the very limited information gathered in this work and further investigation is required. The only information that can be obtained from these limited studies is that the local symmetry around the extracted $\mathrm{Np}$ (Iv) in the $\mathbf{L}_{\mathbf{I I}}$ case is very different from that of the $\mathbf{L}_{\mathbf{I}}$ extract in $\mathrm{C}_{4} \mathrm{mim} \cdot \mathrm{NTf}_{2}$.

The vis-NIR spectrum of Np- $\mathbf{L}_{\text {II }}$ shows a prominent absorption band between $950-990 \mathrm{~nm}$, which is quite different from the Np(Iv)-ligand spectra under different conditions. ${ }^{43,44,47,49-52}$ The only close resemblances to the present Np- $\mathbf{L}_{\text {II }}$ spectrum can 


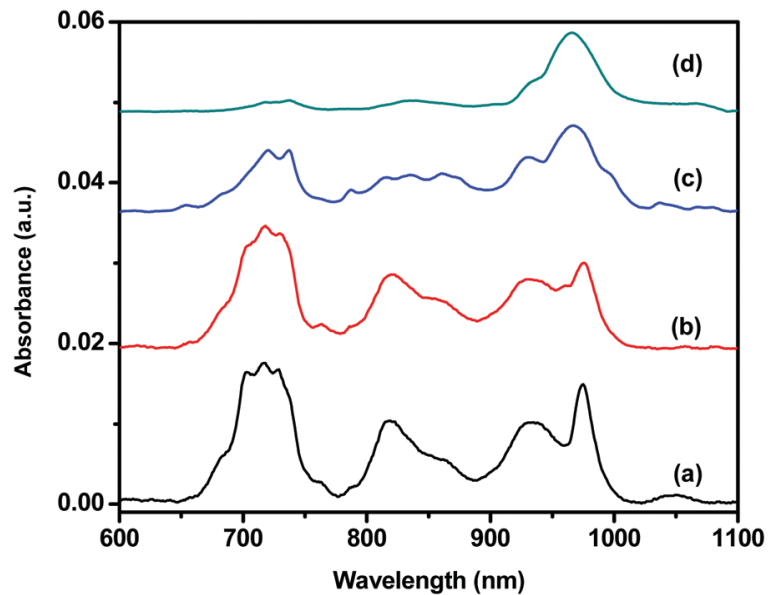

Fig. 5 Vis-NIR absorption spectra of Np(Iv) extract with (a) $\mathbf{L}_{\mathbf{I}}$ and (b) $\mathbf{L}_{\|}$in $5 \%$ isodecanol $+n$-dodecane and (c) $L_{1}$ and (d) $L_{11}$ in $C_{4}$ mim. NTf ${ }_{2} ;[N p]$ : $0.55 \mathrm{mM}$; $\mathrm{T}: 298 \mathrm{~K}$.

be found with $\mathrm{Np}(\mathrm{Iv})$-triamidoamine complexation, ${ }^{45}$ pointing to a possibly similar coordination geometry around $\mathrm{Np}(\mathrm{Iv})$.

The vis-NIR spectra of the extracted Np-L $\left(\mathbf{L}_{\mathbf{I}}\right.$ or $\left.\mathbf{L}_{\text {II }}\right)$ complexes from RTIL and molecular diluent media differ considerably in the present study (Fig. 5), suggesting a difference in the symmetry around $\mathrm{Np}(\mathrm{Iv})$ in the extracted species. This difference may arise from the involvement of a lower number of nitrate ions present in the $\mathrm{Np}(\mathrm{Iv})-\mathrm{L}\left(\mathrm{L}=\mathbf{L}_{\mathbf{I}}\right.$ or $\left.\mathbf{L}_{\text {III }}\right)$ extracted complexes from $\mathrm{C}_{4} \mathrm{mim} \cdot \mathrm{NTf}_{2}$ as compared to those extracted from molecular diluent medium and also may be due to the presence of higher amounts of water/acid in the $\mathrm{C}_{4} \mathrm{mim} \cdot \mathrm{NTf}_{2}$ phase compared to that in a molecular diluent. ${ }^{20}$

The relative position of various $\mathrm{f}-\mathrm{f}$ transitions for the $\mathrm{Np}-\mathbf{L}_{\mathbf{I}}$ and Np- $\mathbf{L}_{\text {II }}$ complexes can be used to get information about the relative complexing strength of the ligands. ${ }^{32,46,53-55}$ The peak positions of the most intense transition of the Np- $\mathbf{L}_{\mathbf{I}}$ and Np- $\mathbf{L}_{\mathbf{I I}}$ complexes are $966 \pm 2 \mathrm{~nm}$ and $738 \pm 2 \mathrm{~nm}$, respectively. Hence, it becomes difficult to comment on the relative stability of the two complexes on the basis of Vis-NIR studies. Some insight into the difference in the complexation ability of $\mathbf{L}_{\mathbf{I}}$ and $\mathbf{L}_{\mathbf{I I}}$ with $\mathrm{Np}^{4+}$ can be gained by cyclic voltammetry studies of the Np- $\mathbf{L}_{\mathbf{I}} /$ $\mathbf{L}_{\mathbf{I I}}$ extracted complexes in the $\mathrm{C}_{4} \mathrm{mim} \cdot \mathrm{NTf}_{2}$ medium (vide infra).

\section{Back extraction and radiation stability studies}

For a sustainable extraction system, it is required to check the back extraction and reusability of the solvent by studying its radiation stability. As seen from Fig. 3a, the back extraction of the extracted $\mathrm{Np}(\mathrm{IV})-\mathrm{L}\left(\mathrm{L}: \mathbf{L}_{\mathbf{I}}\right.$ or $\left.\mathbf{L}_{\mathbf{I I}}\right)$ complexes from $\mathrm{C}_{4} \mathrm{mim} \cdot \mathrm{NTf}_{2}$ merely by acid concentration adjustment was difficult. Hence, different aqueous complexing agents such as oxalic acid and HEDTA (hydroxyethyl ethylenediamine triacetic acid) were used. The ionic liquid phase with Np(Iv)-L (L: $\mathbf{L}_{\mathbf{I}}$ or $\left.\mathbf{L}_{\mathbf{I I}}\right)$ complex was equilibrated with an aqueous phase containing either $0.1 \mathrm{M}$ HEDTA or $0.5 \mathrm{M}$ oxalic acid in $0.5 \mathrm{M} \mathrm{HNO}_{3}$. Quantitative back extraction of $\mathrm{Np}$ (Iv) was observed by both complexing agents (Table 4).
Table 4 Effect of irradiation dose on $D_{\mathrm{Np}(\mathrm{IV})}$ from $0.5 \mathrm{M} \mathrm{HNO}_{3}$ and \% back extraction of $\mathrm{Np}$ (Iv) using different aqueous complexing agents; $0.1 \mathrm{M}$ HEDTA or $0.5 \mathrm{M}$ oxalic acid (OA) in $0.5 \mathrm{M} \mathrm{HNO}_{3}$; Organic phase: $1 \times 10^{-4}$ $\mathrm{L}_{1} / 1 \times 10^{-5} \mathrm{M} \mathrm{L}_{\mathbf{l l}}$ in $\mathrm{C}_{4} \mathrm{mim} \cdot \mathrm{NTf}_{2} ; \mathrm{T}: 298 \mathrm{~K}$

\begin{tabular}{llllll}
\hline & \multicolumn{2}{c}{$D_{\mathrm{Np}(\mathrm{IV})}$ at varying dose } & & \multicolumn{2}{c}{$\begin{array}{l}\text { \% Stripping with } \\
\text { complexing agent }\end{array}$} \\
\cline { 2 - 3 } Ligand & 0 & $300 \mathrm{kGy}$ & & HEDTA & OA \\
\hline $\mathbf{L}_{\mathbf{I}}$ & $6.07 \pm 0.32$ & $0.07 \pm 0.01$ & & $>99 \%$ & $>98 \%$ \\
$\mathbf{L}_{\text {II }}$ & $5.42 \pm 0.41$ & $0.06 \pm 0.01$ & & $>98 \%$ & $>97 \%$ \\
\hline
\end{tabular}

The radiolytic stability is an important parameter to decide the applicability of a given extraction system in the nuclear industry. Therefore, the present solvent system was irradiated with ${ }^{60} \mathrm{Co}$ to a cumulative dose of $300 \mathrm{kGy}$, whereupon the extraction of $\mathrm{Np}$ (rv) was done with the irradiated solvents from a $0.5 \mathrm{M} \mathrm{HNO}_{3}$ solution. The $D_{\mathrm{Np}(\mathrm{IV})}$ decreased drastically upon irradiation, suggesting a poor radiation stability of the present systems at higher irradiation doses (Table 4). In general, the radiolytic stability of RTILs is known to be reasonably good. ${ }^{56,57}$ However, the poor extraction data indicate that the extractant is degrading significantly even in a relatively viscous medium like this RTIL. The degradation products are generally formed from the rupture of the ether linkages and the $\mathrm{N}-\mathrm{C}_{\text {carbonyl }}$ bond. The commonly observed degradation products for DGA based ligands in RTIL are carboxylic acid, hydroxyl acetamides, and octyl as well as fragmented dioctyl diglycolamide radicals. ${ }^{58}$

\section{Cyclic voltammetry studies}

The extraction of $\mathrm{Np}$ (Iv) by $\mathbf{L}_{\mathbf{I}}$ and $\mathbf{L}_{\mathbf{I I}}$ was done at $0.5 \mathrm{M} \mathrm{HNO}_{3}$ to minimize or avoid the uptake of $\mathrm{HNO}_{3}$, which can interfere with the cyclic voltammetry (CV) studies and can also reduce the working potential window. The cyclic voltammogram of the blank $\mathrm{C}_{4} \mathrm{mim} \cdot \mathrm{NTf}_{2}$ does not have any prominent peaks in the potential range of -2 to +2 volt (Fig. 6 (inset)). The CV study was

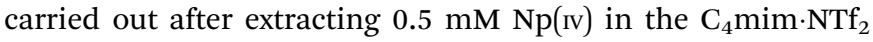

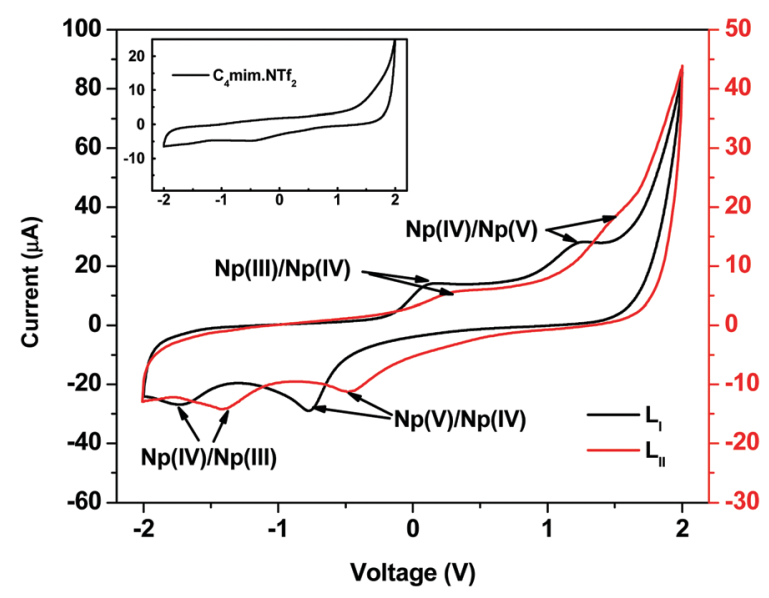

Fig. 6 Cyclic voltammetry studies of the Np-L $\left(\mathbf{L}_{1}\right.$ and $\left.\mathbf{L}_{11}\right)$ complex extracted in $\mathrm{C}_{4} \mathrm{mim} \cdot \mathrm{NTf}_{2}$; [Np]: $0.55 \mathrm{mM}$ for $L_{1}$ and $0.25 \mathrm{mM}$ for $L_{11}$; $T: 298 \mathrm{~K}$. The inset shows the $\mathrm{CV}$ of pristine $\mathrm{C}_{4} \mathrm{mim} \cdot \mathrm{NTf}_{2}$ under similar conditions. 
phase containing $2 \mathrm{mM}$ and $1 \mathrm{mM}$ of $\mathbf{L}_{\mathbf{I}}$ and $\mathbf{L}_{\mathbf{I I}}$, respectively. For the CV study, a three-electrode system consisting of glassy carbon as the working electrode ( $2 \mathrm{~mm}$ diameter disk electrode) and two platinum disk electrodes ( $2 \mathrm{~mm}$ diameter) were used as the counter and the reference electrode. The selection of these electrodes was done based on our previous study where $\mathrm{CV}$ of $\mathrm{Np}$ was done in a $\mathrm{TBP}-\mathrm{C}_{4} \mathrm{mim} \cdot \mathrm{NTf}_{2}$ system. ${ }^{59}$ The cyclic voltammogram of the Np(Iv)-L (L: $\left.\mathbf{L}_{\mathbf{I}} / \mathbf{L}_{\text {II }}\right)$ complex in the RTIL was recorded at a scan rate of $0.1 \mathrm{~V} \mathrm{~s}^{-1}$ and is shown in Fig. 6 . The cyclic voltammograms of both the $\mathbf{L}_{\mathbf{I}}$ and $\mathbf{L}_{\mathbf{I I}}$ containing ionic liquid phases show two prominent peaks in the cathodic scan suggesting two successive reductions and two oxidation peaks in the anodic scan indicating two successive oxidations. The first peak with $\mathrm{Np}-\mathbf{L}_{\mathbf{I}}-\mathrm{C}_{4} \mathrm{mim} \cdot \mathrm{NTf}_{2}$ at $-0.77 \mathrm{~V}$ in the cathodic scan may be due to the reduction of $\mathrm{Np}(\mathrm{v}) \rightarrow \mathrm{Np}(\mathrm{Iv})$, whereas the cathodic peak at $-1.73 \mathrm{~V}$ corresponds to the $\mathrm{Np}(\mathrm{IV}) /$ $\mathrm{Np}$ (III) reduction couple. Similarly, the peaks at +0.10 and $+1.22 \mathrm{~V}$ correspond to the oxidation of the $\mathrm{Np}$ (III)/ $\mathrm{Np}$ (IV) and $\mathrm{Np}(\mathrm{Iv}) / \mathrm{Np}(\mathrm{v})$ couples, respectively, with $\mathrm{Np}-\mathbf{L}_{\mathbf{I}}-\mathrm{C}_{4} \mathrm{mim} \cdot \mathrm{NTf}_{2}$ (Table 5). The corresponding reduction peaks with $\mathrm{Np}-\mathbf{L}_{\mathbf{I I}^{-}}$ $\mathrm{C}_{4} \mathrm{mim} \cdot \mathrm{NTf}_{2}$ are observed at $-0.46 \mathrm{~V}$ and $-1.41 \mathrm{~V}$, respectively, for the $\mathrm{Np}(\mathrm{v}) / \mathrm{Np}$ (Iv) and $\mathrm{Np}$ (Iv)/ $\mathrm{Np}$ (III) couples and the corresponding oxidation peaks are at $+0.28 \mathrm{~V}$ and $+1.50 \mathrm{~V}$ for $\mathrm{Np}$ (III)/ $\mathrm{Np}$ (Iv) and $\mathrm{Np}(\mathrm{Iv}) / \mathrm{Np}(\mathrm{v})$ couples, respectively. The nature of the $\mathrm{CV}$ of $\mathrm{Np}$ with the $\mathbf{L}_{\mathbf{I}} / \mathbf{L}_{\mathbf{I I}}$ ligands in $\mathrm{C}_{4}$ mim $\cdot \mathrm{NTf}_{2}$ is distinctly different from that obtained with the Np-TBP-C $\mathrm{C}_{4} \mathrm{mim} \cdot \mathrm{NTf}_{2}$ system. ${ }^{50}$ In the present study, we observed a reduction in the peak corresponding to the $\mathrm{Np}(\mathrm{v}) / \mathrm{Np}$ (Iv) couple, which is absent in the Np-TBP-C ${ }_{4} \mathrm{mim} \cdot \mathrm{NTf}_{2}$ system. ${ }^{59}$ The presence of $\mathrm{Np}(\mathrm{v})$ in the present system may be due to the in situ aerial oxidation of the $\mathrm{Np}$ (Iv) extract or another possible reason may be the coextraction of $\mathrm{Np}(\mathrm{v})$ (present in traces) with $\mathrm{Np}$ (Iv) due to the cation-cation interaction, as also observed by Sarsfield et al., in the extraction of $\mathrm{Np}$ (Iv) by TBP. ${ }^{60}$ However, the characteristic peak of $\mathrm{Np}(\mathrm{v})$ (at $980 \mathrm{~nm}$ ) is not clearly observed in the corresponding vis-NIR spectrum of the $\mathrm{Np}$ (Iv) extract with $\mathbf{L}_{\mathbf{I}} / \mathbf{L}_{\mathbf{I I}}-\mathrm{C}_{4} \mathrm{mim} \cdot \mathrm{NTf}_{2}$, but a broad peak in the region of 950 $990 \mathrm{~nm}$ may indicate the presence of $\mathrm{Np}(\mathrm{v})$ along with $\mathrm{Np}(\mathrm{Iv})$ in the respective extract (Fig. 5).

The overall nature of the cyclic voltammograms of the Np- $\mathbf{L}_{\mathbf{I}}$ and Np- $\mathbf{L}_{\mathbf{I I}}$ complexes is very similar, except for the shift in both the cathodic and anodic peak potentials. The peak potentials of the Np- $\mathbf{L}_{\mathbf{I I}}$ complex are at lower values in the cathodic scan (more positive), suggesting easy reduction. The more negative shift in the cathodic scan points to better complexation. ${ }^{55,61,62}$ Sengupta et al. have also observed that the reduction potentials $(\mathrm{Np}(\mathrm{Iv}) /(\mathrm{III}))$ are more negative for Np-TODGA compared to the

Table 5 Peak potentials (V) observed for different couples in the CV study of Np- $L_{1}$ and Np- $L_{11}$ complexes extracted in $\mathrm{C}_{4}$ mim.NTf2 at $298 \mathrm{~K}$

\begin{tabular}{|c|c|c|}
\hline Redox couple & $\mathrm{Np}-\mathbf{L}_{\mathbf{I}}$ & $\mathrm{Np}-\mathbf{L}_{\mathbf{I I}}$ \\
\hline $\mathrm{Np}(\mathrm{v}) \rightarrow \mathrm{Np}(\mathrm{Iv})$ & -0.77 & -0.46 \\
\hline $\mathrm{Np}(\mathrm{IV}) \rightarrow \mathrm{Np}$ (III) & -1.73 & -1.41 \\
\hline $\mathrm{Np(III)} \rightarrow$ Np(Iv) & +0.10 & +0.28 \\
\hline $\mathrm{Np}(\mathrm{IV}) \rightarrow \mathrm{Np}(\mathrm{v})$ & +1.22 & +1.50 \\
\hline
\end{tabular}
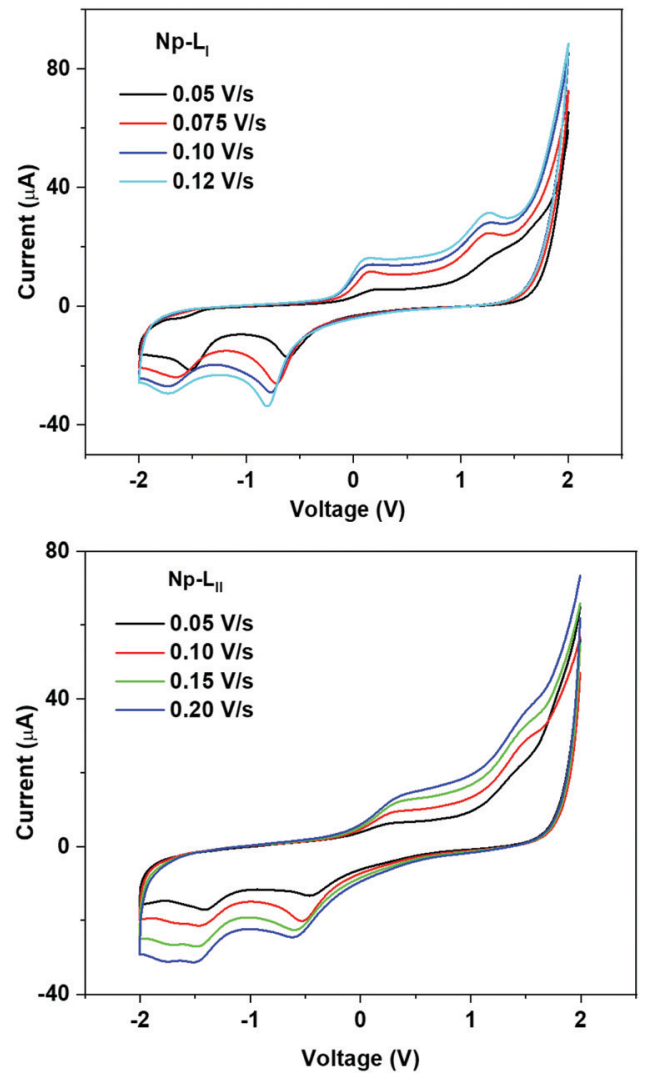

Fig. 7 Cyclic voltammetry studies of the extracted $\mathrm{Np}$ (IV) complex with (a) $L_{1}$ and (b) $L_{\| 1}$ dissolved in $C_{4}$ mim. $N T f_{2}$ at different scan rates; $T: 298 \mathrm{~K}$.

Np-DGA-TSIL extracted complex in ionic liquid, suggesting the better stability of the former complex. ${ }^{62}$ In the present study, the Np(Iv)- $\mathbf{L}_{\mathbf{I}}$ system is at a more negative potential than that of

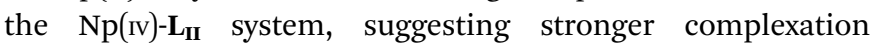
with the former ligand. On the other hand, the $D$-value of $\mathrm{Np}$ (Iv) was found to be higher with $\mathbf{L}_{\mathbf{I I}}$ (vide supra), indicating that the hydrophobicity of the ML complex, the phase transfer energetics, the solvation of the ML solvates, etc., may be significant factors in the extraction of metal ions along with the ML complexation strength.

Scan rate variation experiments (Fig. 7a and b) were carried out to get information about the reversibility of the Np couple. They can be used to deduce the diffusion coefficient of the electroactive species under suitable conditions.

The Randles-Sevcik expression (eqn (3)) can be used for the calculation of the diffusion coefficient $(D)$ of the $\mathrm{Np}-\mathrm{L}$ (L: $\mathbf{L}_{\mathbf{I}}$ or $\mathbf{L}_{\mathbf{I I}}$ ) species in the present system.

$$
i_{p}^{c}=0.496 \cdot n F C A D^{1 / 2}\left(\frac{\alpha n_{\alpha} F v}{R T}\right)^{1 / 2}
$$

where $n$ is the number of electrons involved, $F$ is the Faraday constant, $A$ is the area of the electrode $\left(\mathrm{cm}^{2}\right), C_{\mathrm{o}}$ is the bulk concentration of the oxidized species $\left(\mathrm{mol} \mathrm{cm} \mathrm{cm}^{-3}\right), D$ is the diffusion coefficient $\left(\mathrm{cm}^{2} \mathrm{~s}^{-1}\right), v$ is the scan rate $\left(\mathrm{V} \mathrm{s}^{-1}\right)$, $R$ is the gas constant, and $T$ is the temperature in $\mathrm{K}$. The value 
of $\alpha n_{\alpha}$ can be obtained from the CV data at a given scan rate by using eqn (4).

$$
\left|E_{p}^{c}-E_{p / 2}^{c}\right|=\frac{1.857 R T}{\alpha n_{\alpha} F}
$$

Eqn (3) shows that the intercept of $I_{\mathrm{c}} v s . v^{1 / 2}$ should pass through the origin. ${ }^{63}$ Although the linear fit to the plot gives $R^{2}>0.95$ (ESI) it does not pass through the origin, so the diffusion coefficient calculated in the present system may have significant errors and hence, not listed here. The scan rate variation studies show a change in the cathodic peak potential towards the left (more negative value) with the scan rate for

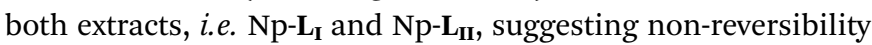
or a quasi-reversible nature of the reduction process. ${ }^{63-65}$

\section{Conclusions}

Solutions of $\mathbf{L}_{\mathbf{I}}$ and $\mathbf{L}_{\text {II }}$ in the RTIL $\mathrm{C}_{4} \mathrm{mim} \cdot \mathrm{NTf}_{2}$ were evaluated for the extraction of $\mathrm{Np}$ (Iv) ions to investigate its applicability in back-end processes. The extraction of Np(Iv) was higher in the RTIL medium as compared to that in a molecular diluent at lower acid concentrations, while the situation changed at higher acid concentrations. This arises due to difference in the extraction mechanisms at higher acidity. Interestingly, 1:1 ligand-Np(Iv) extracted complexes were formed both in RTIL and in molecular diluents. $\mathrm{Np}$ (Iv) was extracted to a larger extent by $\mathbf{L}_{\mathbf{I I}}$ than $\mathbf{L}_{\mathbf{I}}$ in $\mathrm{C}_{4} \mathrm{mim} \cdot \mathrm{NTf}_{2}$. The nature of the extracted complexes was ascertained by slope analysis and was also studied by vis-NIR spectrophotometry and cyclic voltammetry. The vis-NIR studies indicate a difference in the nature of the extracted Np-L complex in RTIL compared to that in a $5 \%$ isodecanol $+95 \% n$-dodecane mixture. The peak positions of the $\mathrm{f}-\mathrm{f}$ transition for the $\mathrm{Np}-\mathrm{L}_{\mathbf{I}}$ and $\mathrm{Np}-\mathbf{L}_{\mathbf{I I}}$ extracted complexes in $\mathrm{C}_{4} \mathrm{mim} \cdot \mathrm{NTf}_{2}$ were found to be very close (within $\pm 2 \mathrm{~nm}$ ) making it difficult to comment on the relative stability of the two complexes in $\mathrm{C}_{4} \mathrm{mim} \cdot \mathrm{NTf}_{2}$ solely based on vis-NIR studies. The CV studies were done to understand the relative stability of the Np- $\mathbf{L}_{\mathbf{I}}$ and $\mathbf{N p}-\mathbf{L}_{\mathbf{I I}}$ extracted complex in $\mathrm{C}_{4} \mathrm{mim} \cdot \mathrm{NTf}_{2}$ medium. The CV studies showed relatively strong complexation of $\mathrm{Np}-\mathbf{L}_{\mathbf{I}}$ compared to $\mathrm{Np}-\mathbf{L}_{\mathbf{I I}}$, where the extraction of $\mathrm{Np}$ was higher for the latter. Though the back extraction of the extracted metal ion was quite efficient using either oxalic acid/HEDTA, the radiolytic stability of the ligand solutions in RTIL was rather poor suggesting that long term use in a high radiation field was not recommended.

\section{Experimental}

\section{Materials}

The DGA-functionalized poly(propylene imine) diaminobutane dendrimers $\mathbf{L}_{\mathbf{I}}$ and $\mathbf{L}_{\mathbf{I I}}$ were prepared as per the procedure described previously. ${ }^{66}$ NMR spectroscopy and HR-MS were used to check the purity of the ligands. $\mathrm{C}_{4} \mathrm{mim} \cdot \mathrm{NTf}_{2}$, $n$-dodecane and isodecanol ( $>99 \%$ purity) were obtained from Iolitec, Germany, Lancaster, UK, and SRL, Mumbai, respectively, and were used as received. Nitric acid solutions of different molarity were prepared from Suprapur nitric acid (Merck, Germany) and MilliQ water (Millipore) and standardized using a conventional acid-base titrimetric method using AR grade $\mathrm{NaOH}(\mathrm{BDH})$ with phenolphthalein (Fluka, Switzerland) as the indicator. Oxalic acid dihydrate (Thomas Baker, $>99 \%$ ) and HEDTA (Sigma-Aldrich, > 99\%) for the back extraction studies were used as received without any purification.

\section{Radiotracer}

The ${ }^{239} \mathrm{~Np}$ tracer was purified from a neutron irradiated $\mathrm{UO}_{2}\left(\mathrm{NO}_{3}\right)_{2} \cdot 6 \mathrm{H}_{2} \mathrm{O}$ target by extracting it, after $\mathrm{Np}$ oxidation state adjustment to $\mathrm{Np}$ (Iv) (vide infra), with $0.5 \mathrm{M}$ TTA (2-thenoyl trifluoroacetone; Sigma-Aldrich) in xylene at $1 \mathrm{M} \mathrm{HNO}_{3}$, followed by its subsequent back extraction in $8 \mathrm{MHNO}_{3}$. The resulting $\mathrm{Np}$ (Iv) aqueous solution was washed several times with xylene to remove any traces of organic impurities. The purity of the stock ${ }^{239} \mathrm{~Np}$ was checked by gamma as well as alpha spectrometry.

\section{Oxidation state adjustment}

A freshly prepared solution of ferrous sulfamate $(0.3 \mathrm{M})$ was used along with a few drops of hydroxylamine nitrate $(1 \mathrm{M})$ as the reductant for the conversion of $\mathrm{Np}$ to the $\mathrm{Np}$ (Iv) state. The oxidation state of $\mathrm{Np}$ in the stock solution was confirmed intermittently by TTA extraction for tracer ${ }^{239} \mathrm{~Np}$ (ESI $\dagger$ ), whereas vis-NIR spectroscopy was applied for the ${ }^{237} \mathrm{~Np}$ solution by monitoring the reduction of the peak at $980 \mathrm{~nm}(\mathrm{~Np}(\mathrm{v})$ signature) with the formation of the peak at $964 \mathrm{~nm} \mathrm{(Np(Iv)}$ signature). ${ }^{59,67}$

\section{Distribution studies}

Stock solutions of $\mathbf{L}_{\mathbf{I}}$ and $\mathbf{L}_{\mathbf{I I}}$ were prepared by dissolving known amounts of the ligands in $\mathrm{C}_{4} \mathrm{mim} \cdot \mathrm{NTf}_{2}$. The ligand solution was diluted as per the experimental requirements. The distribution ratios $(D)$ of $\mathrm{Np}$ (Iv) were measured by equilibrating equal volumes (usually $1 \mathrm{~mL}$ ) of ligand solution in $\mathrm{C}_{4} \mathrm{mim} \cdot \mathrm{NTf}_{2}$ with an aqueous solution containing ${ }^{239} \mathrm{~Np}\left(10^{-12} \mathrm{M}\right)$ in $5 \mathrm{~mL}$ stoppered glass centrifuge tubes for the required time in a constant temperature $\left(25 \pm 0.1{ }^{\circ} \mathrm{C}\right)$ water bath. The glass centrifuge tubes were taken out, rested, and centrifuged at $5000 \mathrm{rpm}$ for $5 \mathrm{~min}$ to get good phase separation. Fixed volumes of both phases $(100 \mu \mathrm{L})$ were removed and assayed using a well type $\mathrm{NaI}(\mathrm{Tl})$ detector coupled with a multichannel analyzer. The $D$ values were determined from the ratio of the activity per minute per unit volume of the organic phase to that in the aqueous phase. All the extraction experiments were carried out in duplicate and the reported values are average values with an error $<5 \%$. The radiolytic stability of the present solvent system i.e. $\mathbf{L}_{\mathbf{I}}\left(10^{-4} \mathbf{M}\right)$ and $\mathbf{L}_{\mathbf{I I}}\left(10^{-5} \mathbf{M}\right)$ dissolved in $\mathrm{C}_{4} \mathrm{mim} \cdot \mathrm{NTf}_{2}$ was investigated by irradiating the solvent system in air with a ${ }^{60} \mathrm{Co}$ gamma irradiator at a dose rate of $5.2 \mathrm{kGy} \mathrm{h}^{-1}$. The $D_{\mathrm{Np}(\mathrm{IV})}$ for both the back-extraction of the extracted $\mathrm{Np}$ (Iv) with $\mathbf{L}_{\mathbf{I}}$ or $\mathbf{L}_{\mathbf{I I}}$ and for the radiation stability studies was evaluated as discussed above. 


\section{Absorption studies}

The samples $(\sim 2 \mathrm{~mL})$ for the visible-near infrared (vis-NIR) spectroscopic studies were prepared by liquid-liquid extraction of $\mathrm{Np}(\mathrm{IV})$ using ligand $\left(\mathbf{L}_{\mathbf{I}}\right.$ or $\mathbf{L}_{\mathbf{I I}}$ ) dissolved in $\mathrm{C}_{4} \mathrm{mim} \cdot \mathrm{NTf}_{2}$ or $5 \%$ isodecanol $+n$-dodecane from $0.5 \mathrm{M} \mathrm{HNO}_{3}$. The vis-NIR spectra were recorded using a Jasco-530(V) (Japan) double beam spectrophotometer in the wavelength range of 600-1100 nm. All the spectra were recorded in quartz cuvettes with $10 \mathrm{~mm}$ path length against a suitable blank.

\section{Titration}

The water content in the organic phase was determined with Karl-Fisher (KF) titration using a Titrano 905 from Metrohm. Single solution KF reagent from Merck was used as received. The initial strength (in volume of $\mathrm{KF}$ required/mg of water) of the $\mathrm{KF}$ reagent was determined by titrating a known weight of the water sample with the $\mathrm{KF}$ reagent in triplicate. The $\mathrm{KF}$ strength of the solution was found to be $5.17 \mathrm{~mL} \mathrm{mg}^{-1}$. The acidity of the organic phase was determined by conventional acid-base titration in a neutralized $50 \%$ ethanol-water mixture using standard $\mathrm{NaOH}$ with a phenolphthalein (Merck) indicator.

\section{Electrochemical studies}

$\mathrm{Np}$ (Iv)-L (L: $\mathbf{L}_{\mathbf{I}}$ or $\mathbf{L}_{\mathbf{I I}}$ ) extracts were prepared by equilibration of $2.5 \mathrm{~mL}$ of $1 \mathrm{mM}$ of ligand dissolved in $\mathrm{C}_{4} \mathrm{mim} \cdot \mathrm{NTf}_{2}$ with an

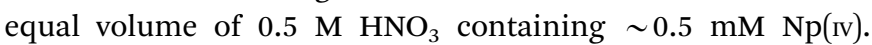
A three-electrode system with a platinum disc ( $2 \mathrm{~mm}$ diameter) both as the counter and reference electrode and glassy carbon ( $2 \mathrm{~mm}$ diameter) as the working electrode were used for the cyclic voltammetry (CV) studies using an AUTOLAB electrochemical setup of Metrohm. Cyclic voltammograms of acid equilibrated ligand solutions in $\mathrm{C}_{4} \mathrm{mim} \cdot \mathrm{NTf}_{2}$ were recorded as the blank to access the working potential window in this medium. All the solutions were purged with high purity $\mathrm{N}_{2}$, at least for 15 min prior to the $\mathrm{CV}$ studies, whereupon a constant $\mathrm{N}_{2}$ atmosphere was maintained.

\section{Conflicts of interest}

There are no conflicts of interest to declare.

\section{Acknowledgements}

The authors (PKV, RBG, BNM, and PKM) sincerely acknowledge Dr P. K. Pujari, Director, Radiochemistry \& Isotope Group, Bhabha Atomic Research Centre, for continuous encouragement.

\section{Notes and references}

1 G. R. Choppin and A. Morgenstern, J. Radioanal. Nucl. Chem., 2000, 243, 45-51.

2 D. D. Sood and S. K. Patil, J. Radioanal. Nucl. Chem., 1996, 203, 547-573.
3 M. Apted and J. Ahn, in Geological Repository Systems for Safe Disposal of Spent Nuclear Fuels and Radioactive Waste, Elsevier, 2010, pp. 3-28.

4 A. Bhattacharyya, P. K. Verma, P. K. Mohapatra, P. K. Pujari, D. Mehta and C. P. Kaushik, Recent trends and strategies in nuclear fuel waste management, 2020.

5 J. N. Mathur, M. S. Murali and K. L. Nash, Solvent Extr. Ion Exch., 2001, 19, 357-390.

6 S. A. Ansari, P. Pathak, P. K. Mohapatra and V. K. Manchanda, Sep. Purif. Rev., 2011, 40, 43-76.

7 Z. Yoshida, S. G. Johnson, T. Kimura and J. R. Krsul, The Chemistry of the Actinide and Transactinide Elements, Springer, Netherlands, Dordrecht, 2007, vol. 44, pp. 699812.

8 Y. Sasaki, Y. Sugo, S. Suzuki and S. Tachimori, Solvent Extr. Ion Exch., 2001, 19, 91-103.

9 R. B. Gujar, G. B. Dhekane and P. K. Mohapatra, Radiochim. Acta, 2013, 101, 719-724.

10 S. A. Ansari, R. B. Gujar, D. R. Prabhu, P. N. Pathak and P. K. Mohapatra, Solvent Extr. Ion Exch., 2012, 30, 457-468.

11 S. A. Ansari, D. R. Prabhu, R. B. Gujar, A. S. Kanekar, B. Rajeswari, M. J. Kulkarni, M. S. Murali, Y. Babu, V. Natarajan, S. Rajeswari, A. Suresh, R. Manivannan, M. P. Antony, T. G. Srinivasan and V. K. Manchanda, Sep. Purif. Technol., 2009, 66, 118-124.

12 G. Modolo, H. Asp, C. Schreinemachers and H. Vijgen, Solvent Extr. Ion Exch., 2007, 25, 703-721.

13 R. B. Gujar, S. A. Ansari, D. R. Prabhu, P. N. Pathak, A. Sengupta, S. K. Thulasidas, P. K. Mohapatra and V. K. Manchanda, Solvent Extr. Ion Exch., 2012, 30, 156-170.

14 M. P. Jensen, T. Yaita and R. Chiarizia, Langmuir, 2007, 23, 4765-4774.

15 P. N. Pathak, S. A. Ansari, S. Kumar, B. S. Tomar and V. K. Manchanda, J. Colloid Interface Sci., 2010, 342, 114-118.

16 M. Iqbal, P. K. Mohapatra, S. A. Ansari, J. Huskens and W. Verboom, Tetrahedron, 2012, 68, 7840-7847.

17 D. Jańczewski, D. N. Reinhoudt, W. Verboom, C. Hill, C. Allignol and M. T. Duchesne, New J. Chem., 2008, 32, 490-495.

18 L. Wu, Y. Fang, Y. Jia, Y. Yang, J. Liao, N. Liu, X. Yang, W. Feng, J. Ming and L. Yuan, Dalton Trans., 2014, 43, 3835-3838.

19 A. Leoncini, S. A. Ansari, P. K. Mohapatra, A. Sengupta, J. Huskens and W. Verboom, Dalton Trans., 2017, 46, 501-508.

20 P. K. Verma, R. B. Gujar, P. K. Mohapatra, S. M. Ali, A. Leoncini, J. Huskens and W. Verboom, New J. Chem., 2021, 45, 9462-9471.

21 P. K. Mohapatra, Dalton Trans., 2017, 46, 1730-1747.

22 P. R. Vasudeva Rao, K. A. Venkatesan, A. Rout, T. G. Srinivasan and K. Nagarajan, Sep. Sci. Technol., 2012, 47, 204-222.

23 A. V. Mudring and S. Tang, Eur. J. Inorg. Chem., 2010, 2569-2581.

24 I. Billard, Handbook on the Physics and Chemistry of Rare Earths, Elsevier B. V., 1st edn, 2013, vol. 43, pp. 213-273.

25 I. Billard, A. Ouadi and C. Gaillard, Anal. Bioanal. Chem., 2011, 400, 1555-1566.

26 X. Sun, H. Luo and S. Dai, Chem. Rev., 2012, 112, 2100-2128. 
27 P. Giridhar, K. A. Venkatesan, S. Subramaniam, T. G. Srinivasan and P. R. Vasudeva Rao, J. Alloys Compd., 2008, 448, 104-108.

28 S. A. Ansari, P. K. Mohapatra and D. R. Raut, J. Solution Chem., 2018, 47, 1326-1338.

29 A. Rout, K. A. Venkatesan, T. G. Srinivasan and P. R. Vasudeva Rao, Sep. Purif. Technol., 2012, 97, 164-171.

30 S. A. Ansari, P. K. Mohapatra, V. Mazan and I. Billard, RSC Adv., 2015, 5, 35821-35829.

31 A. B. Patil, P. Pathak, V. S. Shinde, S. V. Godbole and P. K. Mohapatra, Dalton Trans., 2013, 42, 1519-1529.

32 A. Sengupta, P. K. Mohapatra, P. Pathak, T. K. Ghanty and W. Verboom, New J. Chem., 2017, 41, 836-844.

33 A. Sengupta, P. K. Mohapatra, M. Iqbal, J. Huskens and W. Verboom, Sep. Purif. Technol., 2013, 118, 264-270.

34 G. Suresh, M. S. Murali and J. N. Mathur, Solvent Extr. Ion Exch., 2001, 19, 947-964.

35 M. D. M. Marcos-Arroyo, M. K. Khoshkbarchi and J. H. Vera, J. Solution Chem., 1996, 25, 983-1000.

36 V. A. Cocalia, M. P. Jensen, J. D. Holbrey, S. K. Spear, D. C. Stepinski and R. D. Rogers, Dalton Trans., 2005, 1966-1971.

37 S. A. Ansari, P. Pathak, P. K. Mohapatra and V. K. Manchanda, Chem. Rev., 2012, 112, 1751-1772.

38 A. Bhattacharyya, P. K. Mohapatra, D. R. Raut, A. Leoncini, J. Huskens and W. Verboom, Solvent Extr. Ion Exch., 2018, 36, 542-557.

39 P. K. Mohapatra, M. Iqbal, D. R. Raut, W. Verboom, J. Huskens and V. K. Manchanda, J. Membr. Sci., 2011, 375, 141-149.

40 A. Bhattacharyya, A. Leoncini, P. K. Mohapatra, P. K. Verma, A. S. Kanekar, A. K. Yadav, S. Jha, D. Bhattacharyya, R. J. M. Egberink, J. Huskens and W. Verboom, Dalton Trans., 2018, 47, 15164-15172.

41 S. A. Ansari, P. K. Mohapatra, A. Leoncini, S. M. Ali, A. Singhadeb, J. Huskens and W. Verboom, Dalton Trans., 2017, 46, 16541-16550.

42 H. A. Friedman and L. M. Toth, J. Inorg. Nucl. Chem., 1980, 42, 1347-1349.

43 J. C. Krupa, Inorg. Chim. Acta, 1987, 139, 223-241.

44 I. May, R. J. Taylor, I. S. Denniss, G. Brown, A. L. Wallwork, N. J. Hill, J. M. Rawson and R. Less, J. Alloys Compd., 1998, 275-277, 769-772.

45 J. L. Brown, A. J. Gaunt, D. M. King, S. T. Liddle, S. D. Reilly, B. L. Scott and A. J. Wooles, Chem. Commun., 2016, 52, 5428-5431.

46 M. A. Brown, A. Paulenova and A. V. Gelis, Inorg. Chem., 2012, 51, 7741-7748.

47 W. T. Carnall, G. K. Liu, C. W. Williams and M. F. Reid, J. Chem. Phys., 1991, 95, 7194-7203.
48 J. P. Hessler and W. T. Carnall, in Lanthanide and Actinide Chemistry and Spectroscopy, ed. N. M. Edelstein, vol. 131, 1980, pp. 349-368.

49 S. K. Cary, M. Livshits, J. N. Cross, M. G. Ferrier, V. Mocko, B. W. Stein, S. A. Kozimor, B. L. Scott and J. J. Rack, Inorg. Chem., 2018, 57, 3782-3797.

50 S. I. Nikitenko and P. Moisy, Inorg. Chem., 2006, 45, 1235-1242.

51 A. B. Yusov and A. M. Fedoseev, Radiochemistry, 2013, 55, 360-365.

52 S. Edwards, F. Andrieux, C. Boxall, M. J. Sarsfield, R. J. Taylor and D. Woodhead, Dalton Trans., 2019, 48, 673-687.

53 M. J. Carrot, C. R. Gregson and R. J. Taylor, Solvent Extr. Ion Exch., 2013, 31, 463-482.

54 S. Edwards, F. Andrieux, C. Boxall, M. J. Sarsfield, R. J. Taylor and D. Woodhead, Dalton Trans., 2019, 48, 673-687.

55 Z. Zhang, B. F. Parker, T. D. Lohrey, S. J. Teat, J. Arnold and L. Rao, Dalton Trans., 2018, 47, 8134-8141.

56 P. K. Verma, R. B. Gujar, A. S. Kanekar, Y. K. Bhardwaj and P. K. Mohapatra, Radiat. Phys. Chem., 2019, 158, 180-187.

57 D. Allen, G. Baston, A. E. Bradley, T. Gorman, A. Haile, I. Hamblett, J. E. Hatter, M. J. F. F. Healey, B. Hodgson, R. Lewin, K. V. Lovell, B. Newton, W. R. Pitner, D. W. Rooney, D. Sanders, K. R. Seddon, H. E. Sims and R. C. Thied, Green Chem., 2002, 4, 152-158.

58 A. Sengupta, P. K. Mohapatra, A. B. Patil, R. M. Kadam and W. Verboom, Sep. Purif. Technol., 2016, 162, 77-83.

59 P. K. Verma, B. Mahanty, R. B. Gujar and P. K. Mohapatra, J. Mol. Liq., 2021, 325, 115144.

60 M. J. Sarsfield, H. E. Sims and R. J. Taylor, Solvent Extr. Ion Exch., 2009, 27, 638-662.

61 D. C. Sonnenberger and J. G. Gaudiello, Inorg. Chem., 1988, 27, 2747-2748.

62 A. Sengupta, M. S. Murali, P. K. Mohapatra, M. Iqbal, J. Huskens and W. Verboom, J. Radioanal. Nucl. Chem., 2015, 304, 563-570.

63 N. Zhu, S. Han, S. Gan, J. Ulstrup and Q. Chi, Adv. Funct. Mater., 2013, 23, 5297-5306.

64 S. I. Nikitenko, C. Cannes, C. Le Naour, P. Moisy and D. Trubert, Inorg. Chem., 2005, 44, 9497-9505.

65 C. J. Rao, K. A. Venkatesan, K. Nagarajan and T. G. Srinivasan, Radiochim. Acta, 2008, 96, 403-409.

66 A. Leoncini, S. A. Ansari, P. K. Mohapatra, A. Sengupta, J. Huskens and W. Verboom, Dalton Trans., 2017, 46, 501-508.

67 P. G. Hagan and J. M. Cleveland, J. Inorg. Nucl. Chem., 1966, 28, 2905-2909. 